\title{
Bilateral blunt carotid artery injury: A case report and review of the literature
}

\author{
S Cheddie, ${ }^{1}$ MMed (Surg), FCS (SA); B Pillay, ${ }^{2}$ FCS (SA), Cert Vascular Surgery; R Goga,${ }^{2}$ FCS (SA) \\ ${ }^{1}$ Department of General Surgery, Nelson R Mandela School of Medicine, University of KwaZulu-Natal, Durban, South Africa \\ ${ }^{2}$ Durban Metropolitan Vascular Services, Inkosi Albert Luthuli Central Hospital, Cato Manor, Durban, South Africa
}

Corresponding author: S Cheddie(scheddie@gmail.com)

\begin{abstract}
A 22-year-old man sustained a strangulation-type injury to the neck, with bilateral blunt carotid artery injuries detected on computed tomography (CT) angiography. His Glasgow Coma Score was 15/15, and he was managed conservatively with therapeutic lowmolecular-weight heparin and antiplatelet therapy. A repeat CT angiogram 6 weeks later showed complete resolution of an intimal flap, and he demonstrated no neurological deterioration. There are no definitive management guidelines regarding this type of injury, and our report emphasises the role of conservative anticoagulation therapy in the management of this rare condition.

S Afr J Surg 2013;51(2):77-78. DOI:10.7196/SAJS.1381
\end{abstract}

We report a case of bilateral internal carotid artery (ICA) injury due to strangulation. At presentation there was no neurological deficit and the diagnosis was made on computed tomography (CT) angiography (CTA). The patient was managed conservatively with low-molecular-weight heparin (LMWH) anticoagulation and antiplatelet therapy, with no neurological sequelae. This approach merits consideration in carefully selected patients with such injuries.

\section{Case report}

A 22-year-old man had an accidental strangulation when a rope encircled his neck while he was riding a horse. At presentation he was haemodynamically stable with a Glasgow Coma Score of $15 / 15$ and no focal neurological signs. The carotid pulses were palpable and equal with no bruits. He had neck crepitus and a non-expanding bilateral neck haematoma. A CT angiogram of the neck vessels (Fig. 1) showed total occlusion of the right ICA (grade IV injury) and a filling defect of the left ICA suggestive of an intimal flap (grade II injury). A CT scan of the brain showed no evidence of cerebral infarction. He was anticoagulated with LMWH and dual antiplatelet therapy with aspirin and clopidogrel and discharged 7 days after admission. At follow-up 1 month later he had no neurological sequelae, and a repeat CT angiogram (Fig. 2) showed resolution of the left ICA intimal flap with continued occlusion of the right ICA. Anticoagulation was stopped and he continued on dual antiplatelet therapy for a further 2 months.

\section{Discussion}

Blunt carotid artery injury (BCI) is rare, with a reported incidence of $0.33 \%$ in some series ${ }^{[1]}$ Despite advances in imaging modalities and management options, the morbidity and mortality associated with $\mathrm{BCI}$ is over $30 \%$, largely due to stroke. ${ }^{[1]}$ Bilateral injuries to the ICA are exceptionally rare, with experience limited to case reports only. ${ }^{[2]}$
A high index of suspicion is essential in detecting this often clinically occult injury. Biffl et al. ${ }^{[3]}$ have shown that aggressive screening using the Denver screening criteria (Table 1) to decide on the need for investigation ${ }^{[4]}$ has increased the detection rate for $\mathrm{BCI}$ from $0.1 \%$ to $0.86 \%$. In addition, they showed an improvement in neurological outcome in asymptomatic BCI patients who were anticoagulated.

Biffl's grading system based on investigative angiographic findings has management and prognostic implications outlined

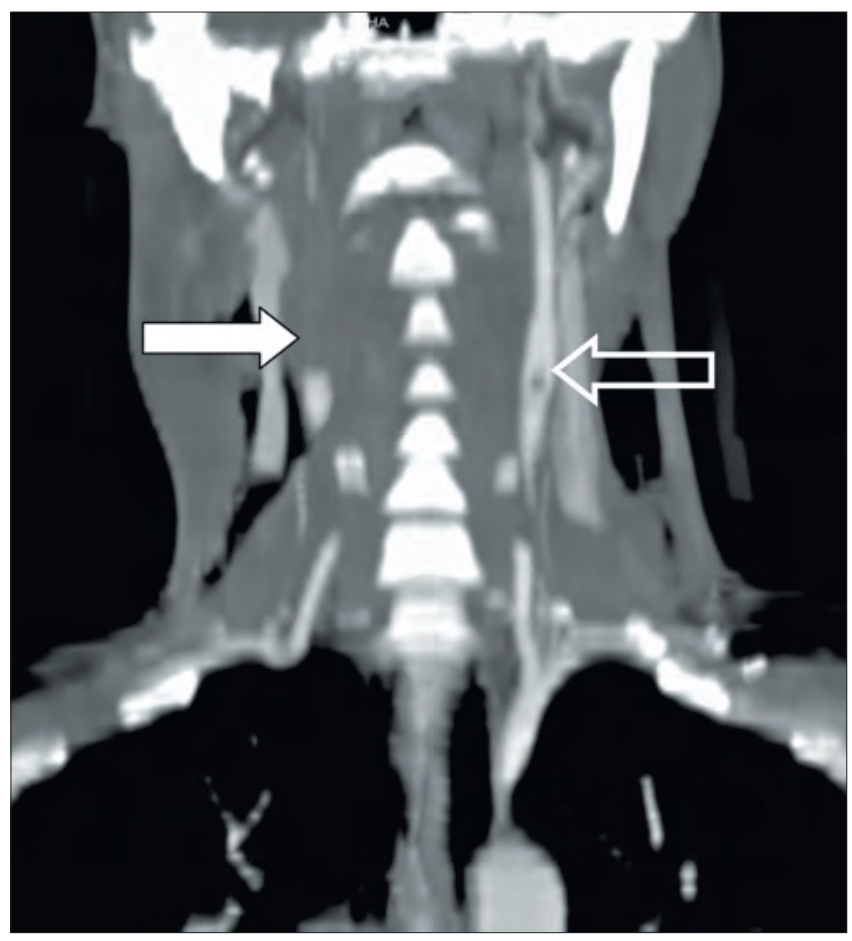

Fig. 1. Computed tomography angiogram showing right internal carotid artery occlusion (closed arrow) and left ICA intimal flap (open arrow). 


\title{
Bilateral blunt carotid artery injury: A case report and review of the literature
}

\author{
S Cheddie, ${ }^{1}$ MMed (Surg), FCS (SA); B Pillay, ${ }^{2}$ FCS (SA), Cert Vascular Surgery; R Goga,${ }^{2}$ FCS (SA) \\ ${ }^{1}$ Department of General Surgery, Nelson R Mandela School of Medicine, University of KwaZulu-Natal, Durban, South Africa \\ ${ }^{2}$ Durban Metropolitan Vascular Services, Inkosi Albert Luthuli Central Hospital, Cato Manor, Durban, South Africa
}

Corresponding author: S Cheddie(scheddie@gmail.com)

\begin{abstract}
A 22-year-old man sustained a strangulation-type injury to the neck, with bilateral blunt carotid artery injuries detected on computed tomography (CT) angiography. His Glasgow Coma Score was 15/15, and he was managed conservatively with therapeutic lowmolecular-weight heparin and antiplatelet therapy. A repeat CT angiogram 6 weeks later showed complete resolution of an intimal flap, and he demonstrated no neurological deterioration. There are no definitive management guidelines regarding this type of injury, and our report emphasises the role of conservative anticoagulation therapy in the management of this rare condition.

S Afr J Surg 2013;51(2):77-78. DOI:10.7196/SAJS.1381
\end{abstract}

We report a case of bilateral internal carotid artery (ICA) injury due to strangulation. At presentation there was no neurological deficit and the diagnosis was made on computed tomography (CT) angiography (CTA). The patient was managed conservatively with low-molecular-weight heparin (LMWH) anticoagulation and antiplatelet therapy, with no neurological sequelae. This approach merits consideration in carefully selected patients with such injuries.

\section{Case report}

A 22-year-old man had an accidental strangulation when a rope encircled his neck while he was riding a horse. At presentation he was haemodynamically stable with a Glasgow Coma Score of $15 / 15$ and no focal neurological signs. The carotid pulses were palpable and equal with no bruits. He had neck crepitus and a non-expanding bilateral neck haematoma. A CT angiogram of the neck vessels (Fig. 1) showed total occlusion of the right ICA (grade IV injury) and a filling defect of the left ICA suggestive of an intimal flap (grade II injury). A CT scan of the brain showed no evidence of cerebral infarction. He was anticoagulated with LMWH and dual antiplatelet therapy with aspirin and clopidogrel and discharged 7 days after admission. At follow-up 1 month later he had no neurological sequelae, and a repeat CT angiogram (Fig. 2) showed resolution of the left ICA intimal flap with continued occlusion of the right ICA. Anticoagulation was stopped and he continued on dual antiplatelet therapy for a further 2 months.

\section{Discussion}

Blunt carotid artery injury (BCI) is rare, with a reported incidence of $0.33 \%$ in some series ${ }^{[1]}$ Despite advances in imaging modalities and management options, the morbidity and mortality associated with $\mathrm{BCI}$ is over $30 \%$, largely due to stroke. ${ }^{[1]}$ Bilateral injuries to the ICA are exceptionally rare, with experience limited to case reports only. ${ }^{[2]}$
A high index of suspicion is essential in detecting this often clinically occult injury. Biffl et al. ${ }^{[3]}$ have shown that aggressive screening using the Denver screening criteria (Table 1) to decide on the need for investigation ${ }^{[4]}$ has increased the detection rate for $\mathrm{BCI}$ from $0.1 \%$ to $0.86 \%$. In addition, they showed an improvement in neurological outcome in asymptomatic BCI patients who were anticoagulated.

Biffl's grading system based on investigative angiographic findings has management and prognostic implications outlined

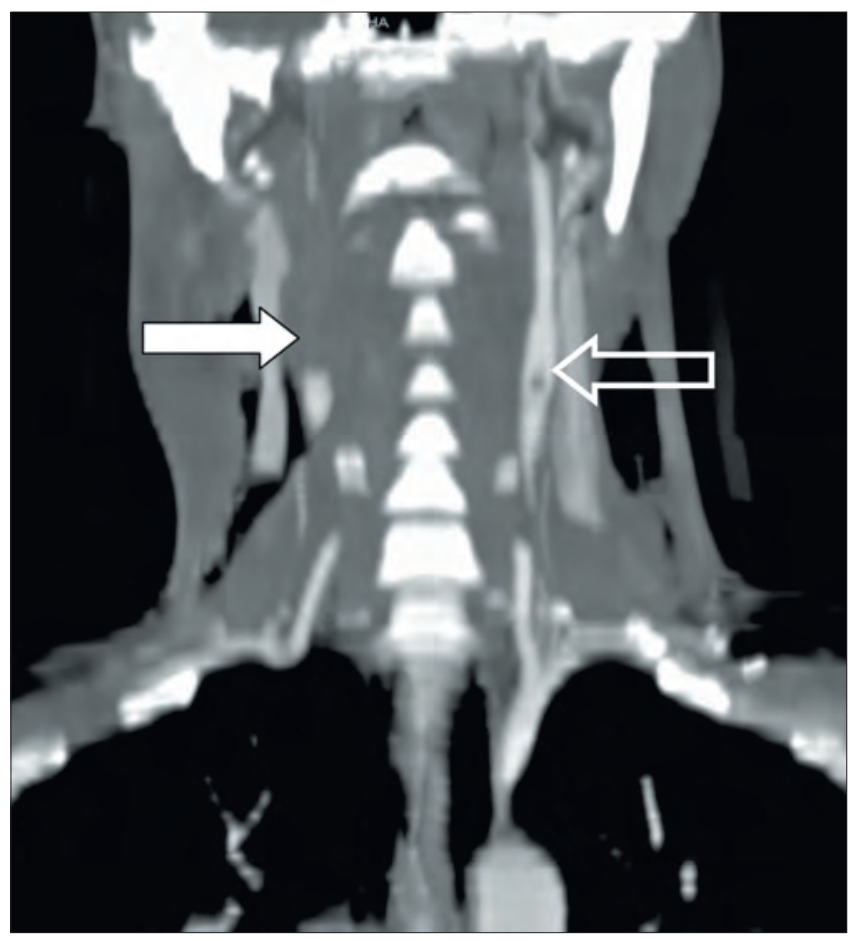

Fig. 1. Computed tomography angiogram showing right internal carotid artery occlusion (closed arrow) and left ICA intimal flap (open arrow). 
in Table 2. ${ }^{[4]}$ Grade I and II injuries are of particular concern and require follow-up angiography owing to the risk of pseudoaneurysm formation despite heparin therapy. ${ }^{[5]}$

Catheter-directed angiography remains the gold standard investigation for the diagnosis of BCI. CTA has delineated this injury adequately. Despite having a sensitivity of $50-68 \%$, it is a

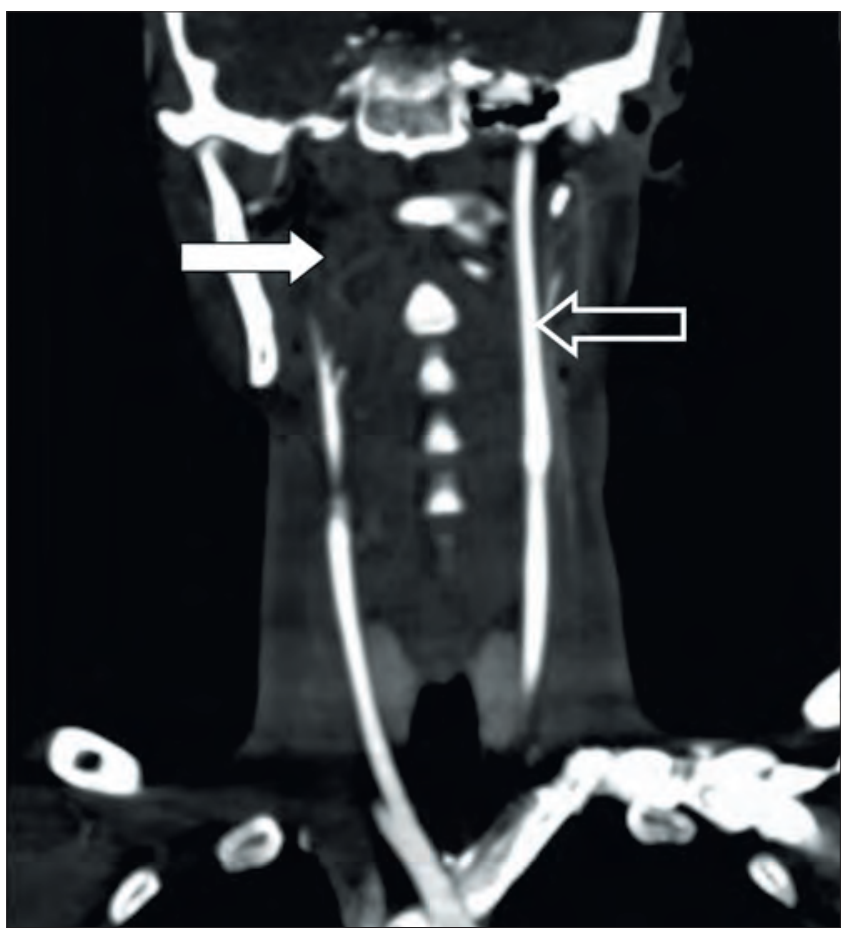

Fig. 2. Follow-up computed tomography angiogram at 6 weeks, showing resolution of the left internal carotid artery intimal flap (open arrow) with persistent occlusion of the right ICA (white arrow). popular diagnostic screening modality because of fast scanning times, and has the added benefit of excluding multiple injuries in the polytrauma patient. Magnetic resonance angiography (MRA) and CTA are equally sensitive in the detection of BCI. MRA has the advantage of detecting early cerebral ischaemia. ${ }^{[6]}$ Duplex scanning has a limited role owing to its inability to accurately assess the distal ICA above the angle of the mandible.

The management of BCI remains controversial without any level I evidence to support clinical guidelines. A beneficial effect of anticoagulation therapy with unfractionated heparin has been demonstrated, with a reduction of the ischaemic stroke rate from $29.8 \%$ to $3.9 \%^{[7]}$ in grade I - IV injuries. A small series by Wahl et al. showed a higher bleeding rate with heparin therapy compared with antiplatelet therapy, and the authors concluded that antiplatelet therapy should be used alone in patients at high risk of bleeding, especially with concomitant intracranial trauma. ${ }^{[8]}$ The use of LMWH has not been described in the literature. With its excellent anticlotting properties and low bleeding complication profile, we believe that it may be the preferable anticoagulation method in these patients.

Open surgery still remains an option in the management of $\mathrm{BCI}$ and is indicated in patients with haemodynamic instability or neurological deterioration despite anticoagulation therapy, and in grade $\mathrm{V}$ injuries. Endovascular stenting is another option particularly useful for high extracranial ICA injuries and pseudoaneurysms where operative access is impossible. ${ }^{[5]}$ Neither of these options was employed in our patient, as there was no neurological progression with his medical therapy.

\section{REFERENCES}

1. Fabian TC, Patton JH, Croce MA, Kudsk KA, Pritchard FE. Blunt carotid injury: Importance of early diagnosis and anticoagulant therapy. Ann Surg 1996;223(5):513-525. [http://dx.doi.org/10.1097/00000658-199605000-00007]

Table 1. The Denver screening criteria for BCI

Signs and symptoms

- Arterial haemorrhage

- Cervical bruit in patient $<50$ years of age

- Expanding cervical haematoma

- Focal neurological deficit

- Neurological examination incongruous with head CT scan findings

- Stroke on secondary CT scan

\section{Risk factors for BCI}

High-energy transfer mechanism with:

- LeForte II or III fracture

- Cervical spine fracture

- Basilar skull fracture with carotid canal involvement

- Diffuse axonal injury with GCS $<6$

- Near-hanging with anoxic brain injury

$\mathrm{CT}=$ computed tomography; $\mathrm{BCI}=$ blunt carotid injury; GCS = Glasgow Coma Score .

Table 2. Biffl grading system - relation of grade to prognosis and therapy

\begin{tabular}{lllll}
\hline Injury grade & Description & Stroke rate (\%) & Mortality rate (\%) & Management \\
\hline I & $\begin{array}{l}\text { Luminal irregularity or dissection with } \\
<25 \% \text { narrowing }\end{array}$ & 3 & 11 & $\begin{array}{l}\text { Anticoagulation + carotid stenting } \\
\text { (if progression of grade I/II injury/ } \\
\text { enlarging pseudo-aneurysm) }\end{array}$ \\
II & $\begin{array}{l}\text { Dissection or intramural haematoma } \\
\text { with }>25 \% \text { luminal narrowing or } \\
\text { intimal flap }\end{array}$ & 11 & 11 & As for grade I \\
III & $\begin{array}{l}\text { Pseudo-aneurysm } \\
\text { Occlusion }\end{array}$ & 33 & 11 & As for grade I \\
IV & Transection with free extravasation & 100 & 22 & Anticoagulation \\
V & & 100 & Open repair
\end{tabular}


2. Kerby J, May A, Gomez C, Rue L. Treatment of bilateral blunt carotid injury using percutaneous angioplasty and stenting: Case report and review of the literature. J Trauma 2000;49(4):784-787. [http://dx.doi.org/10.1097/00005373-20001000000036]

3. Biffl W, Moore EE, Ryu RK, et al. The unrecognized epidemic of blunt carotic arterial injuries: Early diagnosis improves neurologic outcome. Ann Surg 1998:228(4):462-470. [http://dx.doi.org/10.1097/00000658-199810000-00003]

4. Cothren CC, Moore EE, Ray CE Jr, et al. Screening for blunt cerebrovascular injuries is cost-effective. Am J Surg 2005;190(6):849-854. [http://dx.doi.org/10.1016/j. amjsurg.2005.08.007]

5. DuBose J, Recinos G, Teixeira PG, Inaba K, Demetriades D. Endovascula stenting for the treatment of traumatic internal carotid injuries: Expanding experience. J Trauma 2008;65(6):1561-1566. [http://dx.doi.org/10.1097/ TA.0b013e31817fd 954$]$

6. Provenzale JM, Sarikaya B. Comparison of test performance characteristics of MRI $\mathrm{MR}$ angiography, and CT angiography in the diagnosis of carotid and vertebra artery dissection: A review of the medical literature. AJR Am J Roentgenol 2009;193(4):1167-1174. [http://dx.doi.org/10.2214/AJR.08.1688]

7. Biffl W, Ray CE, Moore EE, et al. Treatment related outcomes from blunt cerebrovascular injuries: Importance of routine follow up arteriography. Ann Surg 2002;235(5):699-707. [http://dx.doi.org/10.1097/00000658-200205000-00012]

8. Wahl WL, Brandt MM, Thompson BG, Taheri PA, Greenfield LJ. Antiplatele therapy: An alternative to heparin for blunt carotid injury. J Trauma 2002;52(5):896901. [http://dx.doi.org/10.1097/00005373-200205000-00012] 
in Table 2. ${ }^{[4]}$ Grade I and II injuries are of particular concern and require follow-up angiography owing to the risk of pseudoaneurysm formation despite heparin therapy. ${ }^{[5]}$

Catheter-directed angiography remains the gold standard investigation for the diagnosis of BCI. CTA has delineated this injury adequately. Despite having a sensitivity of $50-68 \%$, it is a

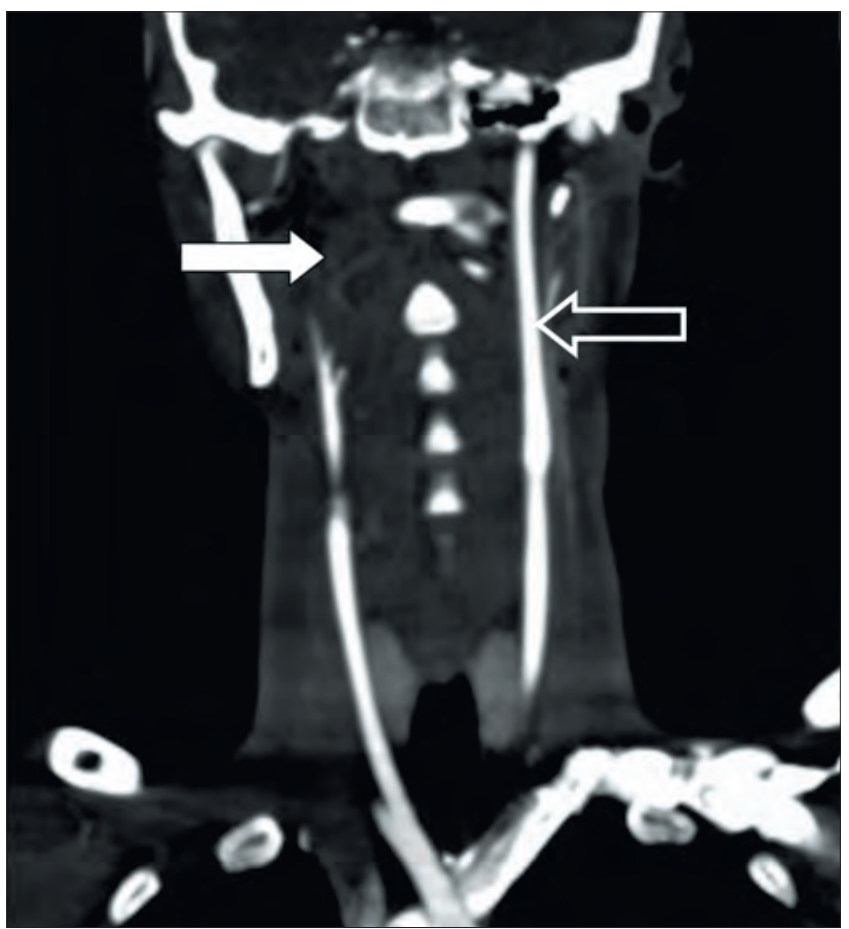

Fig. 2. Follow-up computed tomography angiogram at 6 weeks, showing resolution of the left internal carotid artery intimal flap (open arrow) with persistent occlusion of the right ICA (white arrow). popular diagnostic screening modality because of fast scanning times, and has the added benefit of excluding multiple injuries in the polytrauma patient. Magnetic resonance angiography (MRA) and CTA are equally sensitive in the detection of BCI. MRA has the advantage of detecting early cerebral ischaemia. ${ }^{[6]}$ Duplex scanning has a limited role owing to its inability to accurately assess the distal ICA above the angle of the mandible.

The management of BCI remains controversial without any level I evidence to support clinical guidelines. A beneficial effect of anticoagulation therapy with unfractionated heparin has been demonstrated, with a reduction of the ischaemic stroke rate from $29.8 \%$ to $3.9 \%^{[7]}$ in grade I - IV injuries. A small series by Wahl et al. showed a higher bleeding rate with heparin therapy compared with antiplatelet therapy, and the authors concluded that antiplatelet therapy should be used alone in patients at high risk of bleeding, especially with concomitant intracranial trauma. ${ }^{[8]}$ The use of LMWH has not been described in the literature. With its excellent anticlotting properties and low bleeding complication profile, we believe that it may be the preferable anticoagulation method in these patients.

Open surgery still remains an option in the management of $\mathrm{BCI}$ and is indicated in patients with haemodynamic instability or neurological deterioration despite anticoagulation therapy, and in grade $\mathrm{V}$ injuries. Endovascular stenting is another option particularly useful for high extracranial ICA injuries and pseudoaneurysms where operative access is impossible. ${ }^{[5]}$ Neither of these options was employed in our patient, as there was no neurological progression with his medical therapy.

\section{REFERENCES}

1. Fabian TC, Patton JH, Croce MA, Kudsk KA, Pritchard FE. Blunt carotid injury: Importance of early diagnosis and anticoagulant therapy. Ann Surg 1996;223(5):513-525. [http://dx.doi.org/10.1097/00000658-199605000-00007]

Table 1. The Denver screening criteria for BCI

Signs and symptoms

- Arterial haemorrhage

- Cervical bruit in patient $<50$ years of age

- Expanding cervical haematoma

- Focal neurological deficit

- Neurological examination incongruous with head CT scan findings

- Stroke on secondary CT scan

\section{Risk factors for BCI}

High-energy transfer mechanism with:

- LeForte II or III fracture

- Cervical spine fracture

- Basilar skull fracture with carotid canal involvement

- Diffuse axonal injury with GCS $<6$

- Near-hanging with anoxic brain injury

$\mathrm{CT}=$ computed tomography; $\mathrm{BCI}=$ blunt carotid injury; GCS = Glasgow Coma Score .

Table 2. Biffl grading system - relation of grade to prognosis and therapy

\begin{tabular}{lllll}
\hline Injury grade & Description & Stroke rate (\%) & Mortality rate (\%) & Management \\
\hline I & $\begin{array}{l}\text { Luminal irregularity or dissection with } \\
<25 \% \text { narrowing }\end{array}$ & 3 & 11 & $\begin{array}{l}\text { Anticoagulation + carotid stenting } \\
\text { (if progression of grade I/II injury/ } \\
\text { enlarging pseudo-aneurysm) }\end{array}$ \\
II & $\begin{array}{l}\text { Dissection or intramural haematoma } \\
\text { with }>25 \% \text { luminal narrowing or } \\
\text { intimal flap }\end{array}$ & 11 & 11 & As for grade I \\
III & $\begin{array}{l}\text { Pseudo-aneurysm } \\
\text { Occlusion }\end{array}$ & 33 & 11 & As for grade I \\
IV & Transection with free extravasation & 100 & 22 & Anticoagulation \\
V & & 100 & Open repair
\end{tabular}


2. Kerby J, May A, Gomez C, Rue L. Treatment of bilateral blunt carotid injury using percutaneous angioplasty and stenting: Case report and review of the literature. J Trauma 2000;49(4):784-787. [http://dx.doi.org/10.1097/00005373-20001000000036]

3. Biffl W, Moore EE, Ryu RK, et al. The unrecognized epidemic of blunt carotic arterial injuries: Early diagnosis improves neurologic outcome. Ann Surg 1998:228(4):462-470. [http://dx.doi.org/10.1097/00000658-199810000-00003]

4. Cothren CC, Moore EE, Ray CE Jr, et al. Screening for blunt cerebrovascular injuries is cost-effective. Am J Surg 2005;190(6):849-854. [http://dx.doi.org/10.1016/j. amjsurg.2005.08.007]

5. DuBose J, Recinos G, Teixeira PG, Inaba K, Demetriades D. Endovascula stenting for the treatment of traumatic internal carotid injuries: Expanding experience. J Trauma 2008;65(6):1561-1566. [http://dx.doi.org/10.1097/ TA.0b013e31817fd 954$]$

6. Provenzale JM, Sarikaya B. Comparison of test performance characteristics of MRI $\mathrm{MR}$ angiography, and CT angiography in the diagnosis of carotid and vertebra artery dissection: A review of the medical literature. AJR Am J Roentgenol 2009;193(4):1167-1174. [http://dx.doi.org/10.2214/AJR.08.1688]

7. Biffl W, Ray CE, Moore EE, et al. Treatment related outcomes from blunt cerebrovascular injuries: Importance of routine follow up arteriography. Ann Surg 2002;235(5):699-707. [http://dx.doi.org/10.1097/00000658-200205000-00012]

8. Wahl WL, Brandt MM, Thompson BG, Taheri PA, Greenfield LJ. Antiplatelet therapy: An alternative to heparin for blunt carotid injury. J Trauma 2002;52(5):896901. [http://dx.doi.org/10.1097/00005373-200205000-00012] 